\title{
Variação da qualidade das águas em um rio na região Sudeste do Brasil no longo prazo (1978-2018) segundo os índices IQA e IVA
}

O objetivo deste trabalho foi analisar a tendência de longo prazo do comportamento da qualidade das águas do Rio Jacaré-Guaçu no ponto de monitoramento da CETESB mais a jusante deste rio, próximo à sua foz. O Jacaré-Guaçu é um importante rio da região central do Estado de São Paulo, recebendo através de seus afluentes os despejos das cidades de São Carlos e Araraquara, dentre outras. A análise foi realizada a partir dos resultados dos índices de qualidade IQA e IVA constantes dos relatórios de monitoramento da CETESB, nos períodos de 1978-2018, para o IQA, e de 2002-2018, para o IVA, determinando-se as médias anuais e as médias móveis trienais desses índices. Os resultados mostram para o IQA uma tendência descendente (piora) no período 1981-2003 e ascendente (melhora) entre 2004-2018, sendo que para todo o período estudado a tendência geral é de queda (piora). Para o IVA há uma tendência descendente (melhora) entre 20022013, ascendente (piora) de 2014-2018 e, no geral, entre 2002-2018, de melhora. Foram também determinadas as médias anuais e móveis dos índices para os períodos chuvoso e seco e a tendência resultante foi que tanto o IQA como o IVA apresentam melhores resultados no período seco. Conclui-se que esses índices e respectivas médias móveis se mostraram adequados para se verificar o comportamento da qualidade das águas no ponto estudado, a qual teve uma tendência melhor no período seco, provavelmente devido ao carreamento para o rio pelo escoamento superficial das águas pluviais, de cargas poluidoras difusas.

Palavras-chave: Qualidade das águas; Rio Jacaré-Guaçu; IQA; IVA.

\section{Variation of water quality in a river in the Southeast region of Brazil in the long term (1978-2018) according to the IQA and VAT indices}

\begin{abstract}
The objective of this work was to analyze the long-term trend of water quality behavior of the Jacaré-Guaçu River, at the CETESB monitoring point further downstream of this river, near its mouth. Jacaré-Guaçu is an important river in the central region of the State of São Paulo, receiving through its tributaries discharges of the cities of São Carlos and Araraquara, among others. The analysis was based on the results of the IQA and IVA quality indices contained in CETESB monitoring reports, in the periods 1978-2018, for the IQA, and from 2002-2018, for the IVA, determining the annual averages and the three-year moving averages of these indices. The results show for the IQA a downward trend (worsening) in the period 1981-2003 and ascending (improvement) from 2004-2018, and for the entire period studied the general trend is downward (worsening). For IVA there is a downward trend (improvement) from 2002-2013, upward (worsening) in 20142018 and, overall, from 2002-2018, an improvement. The annual and moving averages of the indices for the rainy and dry periods were also determined and the resulting trend was that both IQA and IVA show better results in the dry period. It was concluded that these indexes and respective moving averages were adequate to verify the behavior of water quality at the studied point, which had a better trend in the dry period, probably due to the transport of diffuse polluting loads to the river by the surface runoff of rainwater.
\end{abstract}

Keywords: Water quality; Jacaré-Guaçu River; IQA; IVA.

Topic: Uso de Recursos Naturais

Reviewed anonymously in the process of blind peer.
Received: 04/07/2021

Approved: 27/07/2021
Gabriel Feloni Martins do Rosário Universidade de Araraquara, Brasil http://lattes.cnpq.br/1228935054877449 http://orcid.org/0000-0002-2068-2438 gabriel.feloni@usp.br

Nemesio Neves Batista Salvador (it) Universidade de Araraquara, Brasil http://lattes.cnpq.br/9930582531600560 http://orcid.org/0000-0002-4158-1951 nemesio.salvador@gmail.com

Daiane Raimundo de Barros (iD) Universidade de Araraquara, Brasil http://lattes.cnpq.br/0941769276708291 http://orcid.org/0000-0001-6986-7188 daianeornitho@gmail.com
Referencing this:

ROSÁRIO, G. F. M.; SALVADOR, N. N. B.; BARROS, D. R.. Variação da qualidade das águas em um rio na região Sudeste do Brasil no longo prazo (1978-2018) segundo os índices IQA e IVA. Revista Ibero Americana de Ciências Ambientais, v.12, n.7, p.475-486, 2021. DOI: http://doi.org/10.6008/CBPC2179-6858.2021.007.0041 


\section{INTRODUÇÃO}

Os recursos hídricos com potencial para utilização podem ser considerados limitados; com isso, a forma de utilização e o monitoramento da qualidade de suas águas deve ser melhor observada, permitindo assim o real [...] "direito ao meio ambiente equilibrado, bem de uso comum do povo e essencial à sadia qualidade vida, impondo-se ao Poder Público e à coletividade o dever de defende-lo e preservá-lo para as presentes e futuras gerações" (BRASIL, 1988).

A qualidade da água pode apresentar variações, através da forma de armazenamento, sua circulação e ambiente de origem (REBOUÇAS, 2006). A má utilização dos recursos hídricos aponta uma pior qualidade, sendo a poluição, industrial, agrícola e urbana, responsável por influenciar essa qualidade (GALLO, 2007). De acordo com Branco et al. (1977) os rios naturalmente escoam impurezas, desta forma, apresentam alterações químicas, físicas e em suas características ecológicas.

No Estado de São Paulo, a CETESB - Companhia Ambiental do Estado de São Paulo, começou a monitorar a qualidade da água em 1974 e emitiu o primeiro relatório de qualidade das águas interiores do Estado em 1978, o qual contém dados de qualidade de 1975 a 1978, obtidos por meio de sua rede de monitoramento (CETESB, 2019a). O objetivo dos relatórios de qualidade das águas é diagnosticar a evolução da qualidade das águas no Estado de São Paulo por meio de inúmeros pontos de amostragem. Em 1974, a rede de monitoramento contava inicialmente com 47 pontos e em 2017 monitorava 471 pontos, alocados por todo o Estado (CETESB, 2019a). Esses pontos permitem um diagnóstico mais abrangente e detalhado da qualidade dos recursos hídricos, o que vem sendo feito de forma sistemática desde 1978. Desde então, o relatório anual é publicado ininterruptamente, o que possibilitou no presente estudo uma análise coesa de longo prazo.

Os relatórios da CETESB apresentam atualmente resultados de diversos parâmetros e índices de qualidade da água, dentre estes, o IQA (Índice de Qualidade das Águas) e o IVA (Índice de Qualidade das Águas para Proteção da Vida Aquática e de Comunidades Aquáticas), compostos por vários parâmetros de qualidade e ecológicos (CETESB, 2019b). Esses índices foram adotados neste estudo por serem considerados representativos da qualidade geral do recurso hídrico monitorado. O IQA é determinado pela CETESB desde 1975 e o IVA, a partir de 2002.

O IQA varia de zero (pior qualidade) a 100 (melhor qualidade), sendo composto por nove parâmetros: Coliformes Fecais, pH, Demanda Bioquímica de Oxigênio (DBO), Nitrogênio Total, Fósforo Total, Temperatura, Turbidez, Resíduo Total e Oxigênio Dissolvido (CETESB, 2019b). Boso et al. (2015) afirmam que o peso atribuído a cada parâmetro determina os indicadores de qualidade da água para humanos e organismos aquáticos. O IQA possui uma conotação mais sanitária, embora os parâmetros DBO, Oxigênio Dissolvido, Nitrogênio Total, e Fósforo Total e indiquem preliminarmente determinadas condições ecológicas.

Considerando as limitações do IQA, trata-se de um índice utilizado em estudos ao redor do mundo, como nos EUA, México, Turquia, Índia, Iraque, Irã, Bangladesh, Indonésia, entre outros, entretanto, esses 
estudos não se utilizam do mesmo padrão para o cálculo do IQA. Em estudo revisando a evolução do IQANSF, alguns estudiosos concluíram que o IQA-NSF sofreu varia mudanças ao longo do tempo, entretanto a ponderação dos parâmetros raramente é levada em conta, sendo necessários definir o tipo de uso da água. O trabalho ainda aborda que é possível notar que os estudos mais recentes para o cálculo do IQA-NSF se baseiam na lógica difusa, sendo essa uma forma de lógica de muitos valores que expressa a verdade parcial entre ser falso ou verdadeiro. Ao longo do tempo os índices de qualidade da água foram se aprimorando, entretanto, o IQA utilizado pela CETESB é o mesmo da década de 70.

A avaliação de House, apresenta vantagens para a utilização do IQA, sendo o resumo da qualidade em um único valor, tornando-o replicável e rápido, a variação do índice em escala numérica como facilidade para sua avaliação, permitindo assim observar possíveis alterações da qualidade nos corpos hídricos; a utilização do IQA associado a classificação do corpo d'água pode proporcionar a identificação das águas superficiais prioritárias; o IQA como facilitador na comunicação com o público leigo, proporcionando assim uma melhor compreensão quanto aos seu valores.

Alguns autores concluem que a qualidade da água varia de acordo com o tipo de uso, e o critério para uma água 'aceitavel' varia de região para região. Concluem ainda que a transformação de uma gama de dados em um unico valor, ainda sim é necessária. O tempo de amostragem também influi de forma significativa nos parametros utilizados, pois influenciam no valor final dos indices. Os autores reforçam ser dificil o desenvolvimento de um único indice geral para a qualidade da água, entretanto, indices locais podem ser desenvolvidos mais fácilmente, embora, afirmem que o indice mais amplo seria ideal, porém os parametros utilizados devem ser cuidadosamente selecionados.

O IVA varia de 1,7 (melhor qualidade) a 15,8 (pior qualidade) e é um índice qualitativamente mais abrangente, composto por dois índices - Índice de Variáveis Mínimas para a Preservação da Vida Aquática (IPMCA) e Índice de Estado Trófico (IET). O IPMCA é composto por um grupo de variáveis essenciais (Oxigênio Dissolvido, pH e Toxicidade pela Ceriodaphnia dúbia, utilizada pela CETESB/SP) e por um grupo de substâncias tóxicas (metais pesados e surfactantes). O IET é composto pelo Índice do Estado Trófico para o Fósforo IET(PT) e pelo Índice do Estado Trófico para a Clorofila $a$ - IET(CL), que indicam os diferentes graus de trofia dos corpos d'água: Ultraoligotrófico, Oligotrófico, Mesotrófico, Eutrófico, Supereutrófico e Hipereutrófico (CETESB, 2019b). O IVA tem uma conotação mais ecológica e de certa forma complementa o IQA, pois leva em conta importantes aspectos de toxicidade que este não considera, assim como o aspecto de trofia, considerado no IQA de modo parcial, relativamente apenas ao parâmetro Fósforo Total.

Analisar o histórico de valores dos índices é um método alternativo, que pode indicar mudanças na qualidade da água da bacia hidrográficas ao longo do tempo, devido a comportamentos antrópicos ou naturais (DONADIO et al., 2005; LOPES et al., 2008). 


\section{REVISÃO TEÓRICA}

\section{Objeto do Estudo}

O ponto de monitoramento objeto deste estudo, codificado pela CETESB como JCGU 03900 (antigo

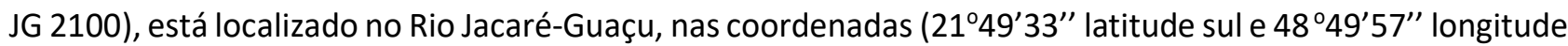
oeste), na Unidade de Gerenciamento de Recursos Hídricos do Tietê-Jacaré - UGRHI 13, região sudeste do Brasil (Figura 1).

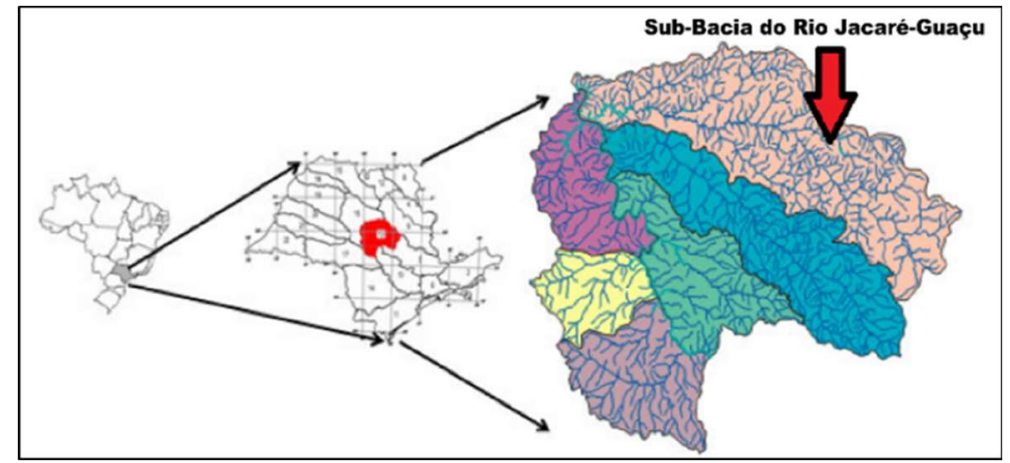

Figura 1: Localização da Unidade de Gerenciamento de Recursos Hídricos do Tietê-Jacaré e suas Sub-Bacias. Fonte: Adaptado de Instituto Pró-Terra (2013).

De acordo com o CBH-TJ (ARARAQUARA, 2019), a Sub-Bacia Jacaré-Guaçu, é detentora de 35\% do total da área da UGRHI 13. Conta com municípios inseridos integral e parcialmente na Sub-Bacia, dentre eles, os municípios de Nova Europa e Gavião Peixoto e, parcialmente, os municípios de Araraquara, São Carlos, Ibitinga, Boa Esperança do Sul, Brotas, Analândia, Ibaté, Matão, Ribeirão Bonito, Dourado, Tabatinga, Itirapina e Trabiju.

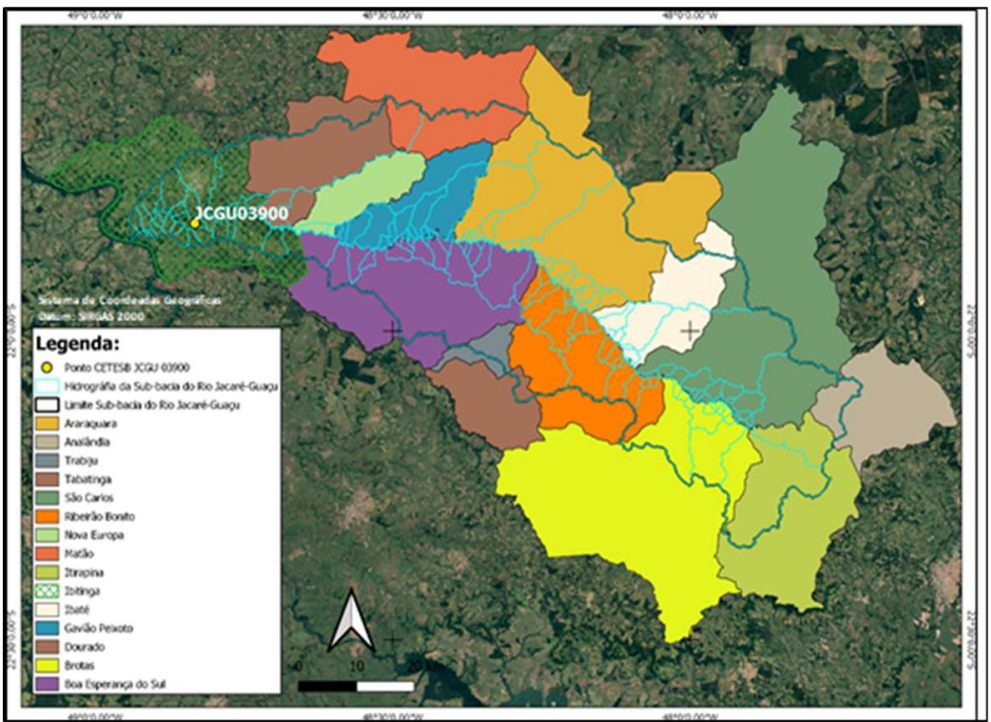

Figura 2: Mapa de municípios, hidrografia, Sub-Bacia do Rio Jacaré-Guaçu e ponto CETESB JCGU 03900. Fonte: Adaptado de CETESB (2019b).

A Sub-Bacia se localiza sobre as formações rochosas Serra Geral, Botucatu, vale dos Rios do Peixe, Piramboia, Itaqueri e Corumbataí (PERROTA et al., 2005). Conforme a classificação de Koppen, o clima nessa Sub-Bacia se encontra entre subtropical úmido ( $\mathrm{Cwa}$ ) de outubro a março e inverno seco ( $\mathrm{Cwb}$ ), de abril a setembro (ALVARES et al., 2013). A temperatura média anual varia entre $15^{\circ} \mathrm{C}$ e $22^{\circ} \mathrm{C}$ IBGE e, segundo Souza et al. (2017), a precipitação média anual se encontra entre 1.313 e $1.680 \mathrm{~mm}$. A vegetação nativa é formada 
pela Floresta Estacional Semidecidual e Savana (cerrado) (INSTITUTO PRÓ-TERRA, 2013).

A rede de monitoramento da CETESB possui ao longo do Rio Jacaré-Guaçú três pontos em ambientes lóticos e um ponto em ambiente lêntico. Para o presente estudo foram utilizados os dados do JCGU 03900, situado no Rio Jacaré-Guaçu (ambiente lótico), no município de Ibitinga (CETESB, 2019a), conforme pode ser visualizado na Figura 2.

O mapa da Figura 3 apresenta o uso e ocupação do solo na Sub-Bacia do Rio Jacaré-Guaçu, as áreas urbanizadas representam cerca de 6,6\% de sua área total (VETIVER, 2016). Os principais municípios, Araraquara e São Carlos, apresentam um grau de urbanização de 97,16\% e 96\% respectivamente.

As principais atividades industriais dessa Sub-Bacia baseiam-se na indústria de metal mecânica, bebidas, papel, tecidos, contudo, destacam-se as indústrias sucroalcoleiras e citrícolas (CPTI, 2008). Cerca de 70,5\% de sua área possui uso agropecuário intensivo, predominando as culturas de cana-de-açúcar, citros, silvicultura (eucalipto e pinus) e as pastagens, havendo também diversas atividades de mineração (VETIVER, 2016). As atividades agropecuárias predominantes mencionadas, utilizam intensivamente agrotóxicos e/ou fertilizantes agrícolas.

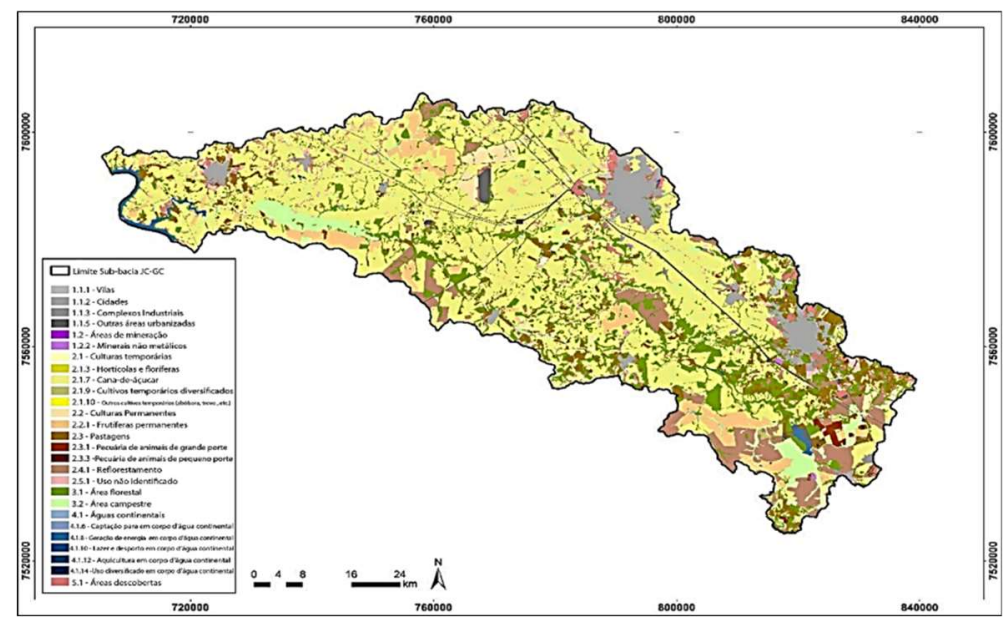

Figura 3: Mapa de uso e ocupação do solo na Sub-bacia do Jacaré-Guaçu. Fonte: Adaptado de Vetiver (2016).

\section{METODOLOGIA}

Com base nas informações e dados da CETESB, utilizando o IQA constante em seus relatórios de 1978 a 2018 (CETESB, 2019a) e o IVA, nos relatórios entre 2002 e 2018 (CETESB, 2019b), foi observado o comportamento da qualidade das águas na Sub-Bacia do Rio Jacaré-Guaçu, no ponto JCGU 03900. Este ponto foi escolhido com base na sua localização, a jusante dos dois principais municípios da Sub-Bacia Jacaré-Guaçu, São Carlos e Araraquara, tendo em vista que ambos municípios são os maiores contribuintes de efluentes domésticos e industriais, além de ser o ponto com maior quantidade de dados disponíveis dentre os monitorados nessa Sub-Bacia.

A modelagem dos dados partiu da média mensal dos índices IQA e IVA. A partir dos dados obtidos nos relatórios, foram determinadas a média aritmética anual e a média móvel aritmética trienal para o IQA e IVA. A média móvel é um parâmetro calculado tendo como início uma série de médias de resultados de diferentes amostras e, que permite no caso, se observar a tendência do comportamento dos referidos índices no longo prazo, atenuando a influência de valores extremos. Segundo Ehlers (2005) a representação gráfica 
de dados ao longo do tempo possibilita revelar padrões de comportamento.

Para a determinação das médias móveis do IQA foram tomados inicialmente os dados do período de 1975 a 1978 e, posteriormente, o cálculo foi feito substituindo o valor do primeiro ano do triênio anterior pelo do ano subsequente a ele, e assim por diante, até o 41ㅇv valor, correspondente ao ano de 2018. Para o IVA o procedimento foi similar, mas a partir do ano de 2002; porém, para esse ano a média móvel considerada foi a própria média anual, uma vez que não haviam dados anteriores do IVA; para 2003, a média móvel considerada foi a média desse ano e do anterior; e a partir de 2004 a determinação passou a ser então trienal. Foram utilizadas as seguintes equações nos cálculos das referidas médias:

Equação 1. Determinação da média móvel IQA

$$
\boldsymbol{M M}_{I Q A}=\frac{\sum_{i}^{2}\left(p_{i-1}+p_{i}\right)+\sum_{3}^{40}\left(p_{i-2}+p_{i-1}+p_{i)}\right)}{\sum_{1}^{40} p_{i}} \quad \text { (Equação 1) }
$$

Onde $\mathrm{MM}=$ média móvel e $\mathrm{P}_{\mathrm{i}}=$ médias anuais do i-ésimo ano.

Equação 2. Determinação da média móvel IVA

$$
\boldsymbol{M M}_{I V A}=\frac{\sum_{i}^{2}\left(p_{i-1}+p_{i}\right)+\sum_{3}^{16}\left(p_{i-2}+p_{i-1}+p_{i)}\right)}{\sum_{1}^{16} p_{i}}(\text { Equação 2) }
$$

Onde $\mathrm{MM}=$ média móvel e $\mathrm{P}_{\mathrm{i}}=$ médias anuais do i-ésimo ano.

Além dos índices IQA e IVA, foram utilizados dados de pluviosidade na Sub-Bacia Jacaré-Guaçu. As informações de pluviosidade foram obtidas a partir do posto pluviométrico C5-081 do DAEE localizado no município de Ibitinga (Latitude S $21^{\circ} 47^{\prime} 07^{\prime \prime}$ e Longitude $048^{\circ} 46^{\prime} 48^{\prime \prime}$ ), selecionado pela sua maior proximidade do corpo d'água, a montante do ponto JCGU 03900, e disponibilidade de dados mais recentes. A partir dos dados obtidos, foram modelados gráficos, onde é possível se observar e analisar as variações de longo prazo dos índices IQA e IVA, considerando inclusive os períodos chuvoso (outubro-março) e seco, de estiagem (abril-setembro).

\section{RESULTADOS E DISCUSSÃO}

\section{Índice de Qualidade das Águas - IQA}

A Figura 4 apresenta os resultados gerais obtidos para a média aritmética anual e a média aritmética móvel do IQA (obtidas a partir da Equação 1), de 1978 a 2018, assim como a classificação deste índice.

Conforme pode ser observado na Figura 4, houve uma tendência geral decrescente (piora) do índice no período estudado, sendo que os primeiros resultados do monitoramento da CETESB apresentaram um IQA com tendência crescente até 1981, com a média anual atingindo 74,1 nesse ano e as médias móveis variando de 68,5 a 70,9. Essas médias tiveram uma queda a partir do ano de 1982, cuja tendência perdurou até 1992, quando atingiu o menor valor, cerca de 60,3. Em 1993 houve um aumento expressivo da média anual, que refletiu numa tendência de alta da média móvel a partir daquele ano, por um breve período, até 1995 e em 1996 a tendência de queda foi retomada, prevalecendo até 2003, ano em que ocorreram os menores valores para a média anual e a média móvel, 53 e 54,6 respectivamente. 


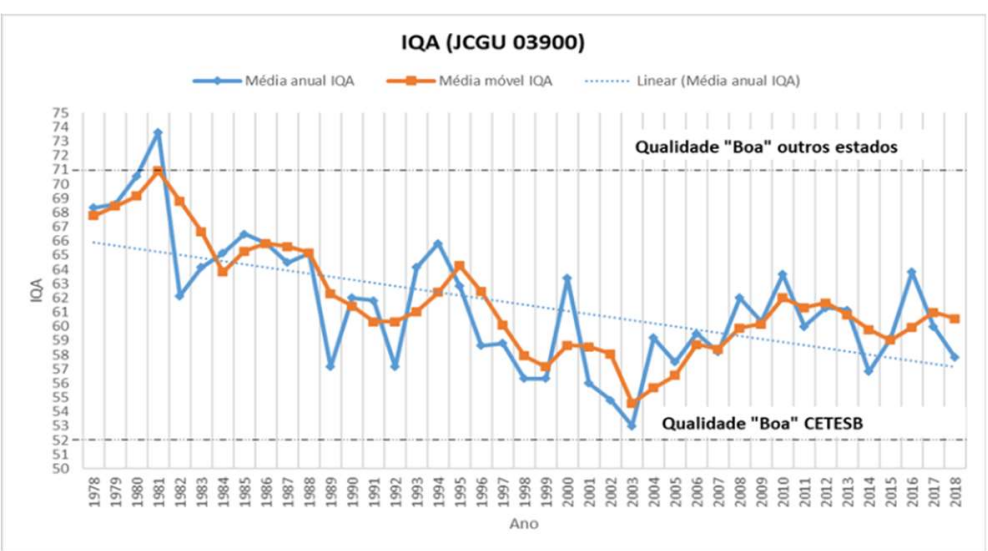

Figura 4: Médias anuais e médias móveis do IQA no ponto JCGU 03900 - 1978 a 2018. Fonte: CETESB (2019a).

Entre as mudanças pontuais observadas, a maior queda na média anual ocorreu entre 1981 e 1982, de 12 pontos no índice, e as maiores altas foram em 1993 e 2000, com elevações de 7,0 e 7,1 pontos respectivamente. Tais oscilações podem ser explicadas por vários motivos, como por exemplo, o lançamento de efluentes com elevada carga poluidora à montante do ponto de monitoramento em dias ou mesmo horas que antecederam as coletas de amostras efetuadas pela CETESB, ou também pela ocorrência de chuvas anteriores às coletas, lixiviando para o referido ponto, através do escoamento superficial das águas pluviais, poluentes que se encontravam sobre o solo (vide item Objeto do Estudo e Figura 3).

A tendência de queda no período de 1981 a 2003, expressa pela média móvel, pode ser explicada por razões estruturais. Por exemplo, na década de 1970 houve expressivo crescimento das cidades e de sua população, assim como da atividade industrial, sendo que naquela época as cidades e muitas indústrias não efetuavam o tratamento adequado de seus efluentes. Além disso, na segunda metade da referida década houve o advento do programa Proálcool, que resultou numa expansão muito grande da cultura da cana e da produção de etanol no estado de São Paulo, bem como da geração de vinhaça, de elevado potencial poluidor, que passou a ser lançada no solo através da fertirrigação, e cuja parcela atingia os corpos d'água por ocasião da ocorrência de chuvas esparsas, após a sua aplicação. Cabe ressaltar também a expansão de outras culturas, como a de citros e eucalipto, que aliadas à da cana, promoveram uma maior aplicação de agrotóxicos e fertilizantes no solo e, consequentemente, parcialmente carreados aos corpos d'água (vide item Objeto do Estudo e Figura 3).

A partir de 2004 o IOA apresenta uma tendência de melhora, sendo que a média móvel teve um comportamento ascendente até 2010, mas de 2011 em diante apresenta uma leve queda, com tendência à estabilidade pelo resto do período, até 2018 (Figura 4). A melhora verificada a partir de 2004 pode ser explicada também por alguns fatores estruturais, tais como: intensificação das intervenções do Ministério Público na segunda metade da década de 1990, no tocante a questões ambientais e de poluição das águas; intensificação das ações do Comitê da Bacia Hidrográfica do Tietê-Jacaré (CBH-TJ), instalado em 1996; incremento do tratamento de efluentes industriais, pela ação da CETESB e pela maior conscientização por parte das próprias indústrias; implementação do tratamento de esgotos em diversas cidades, principalmente nas cidades de Araraquara, em 2000 e de São Carlos, em 2007; e evolução/ aperfeiçoamento das técnicas de manejo e aplicação da vinhaça pela indústria sucroalcoleira. Por outro lado, a queda e estabilidade verificadas 
a partir de 2012 se explicam por fatores como o novo ciclo de expansão das indústrias sucroalcoleiras e da cultura da cana, com a valorização dos biocombustíveis (incluindo o etanol) e com a implementação em muitas dessas indústrias de unidades de geração de energia elétrica (termoelétricas); queda de eficiência das estações de tratamento de esgotos de algumas cidades, inclusive Araraquara e São Carlos; e ocorrência de estiagens mais severas como a ocorrida em 2014 (crise hídrica) no estado de São Paulo e outros estados. É, contudo, evidente, que mesmo as médias móveis apresentando sinais de recuperação, não se observa o retorno da mesma qualidade das águas verificada inicialmente nos primórdios do programa de monitoramento da CETESB, entre os anos 1978 e 1981.

Observando-se ainda a Figura 4, nota-se que tanto a média anual como a média móvel permaneceram na classificação 'boa' do IQA todo o tempo, quando considerado o padrão CETESB. No entanto, nos últimos anos, em função de um maior rigor quanto à qualidade ambiental, incluindo a das águas, outros estados brasileiros passaram a adotar uma classificação do IQA mais rigorosa, conforme pode ser verificado no Quadro 1.

Quadro 1: Faixas de classificação do IQA utilizadas no Brasil.

\begin{tabular}{lll}
\hline Faixas de IQA (outros estados) & Faixas de IQA (CETESB) & Classificação do corpo d'água \\
\hline $\mathbf{9 1 - 1 0 0}$ & $80-100$ & Ótima \\
\hline $\mathbf{7 1 - 9 0}$ & $52-79$ & Boa \\
\hline $\mathbf{5 1 - 7 0}$ & $37-51$ & Razoável \\
\hline $\mathbf{2 6 - 5 0}$ & $20-36$ & Ruim \\
\hline $\mathbf{0 - 2 5}$ & $0-19$ & Péssima \\
\hline
\end{tabular}

Fonte: Adaptado de ANA (2009).

Ao considerar as outras faixas de classificação do IQA utilizadas em outros estados do Brasil, é possível observar uma tolerância maior deste índice por parte da CETESB, sendo que em todo o período considerado ele não atinge a classificação 'boa' adotada por esses estados, ficando praticamente todo o tempo na classificação 'razoável' (IQA 51-70), com exceção apenas do ano de 1980 (vide Figura 4 e Quadro 1).

\section{IQA nos períodos chuvoso e seco}

Outro aspecto de interesse a ser analisado é a tendência do comportamento sazonal do IQA, nos períodos chuvoso e seco. Na Figura 5 são apresentados os resultados obtidos com o desmembramento dos dados para esses dois períodos. Quando se observa na Figura 5 as médias de IQA por período chuvoso e seco, fica evidente que os melhores valores do índice foram encontrados na estiagem e somente no ano de 2015 houve um resultado inferior ao do período chuvoso. Este período resultou indubitavelmente nos piores valores para o IQA, cabendo destaque para 2003, ano do valor mais baixo deste índice.

Resultados similares foram obtidos por Carvalho et al. (2000), estudando alguns ribeirões, em que a classificação 'boa' para o IQA foi observada no inverno, período normalmente menos chuvoso. Por outro lado, Correio et al. (2016) obtiveram resultados contrários, relatando que no corpo hídrico estudado por eles a classificação do IQA foi melhor em períodos de mais alta precipitação. Essas contradições reforçam a dinâmica do processo de variação da qualidade das águas, sujeito à imprevisibilidade das 
precipitações/cargas poluidoras difusas e do lançamento de cargas pontuais.

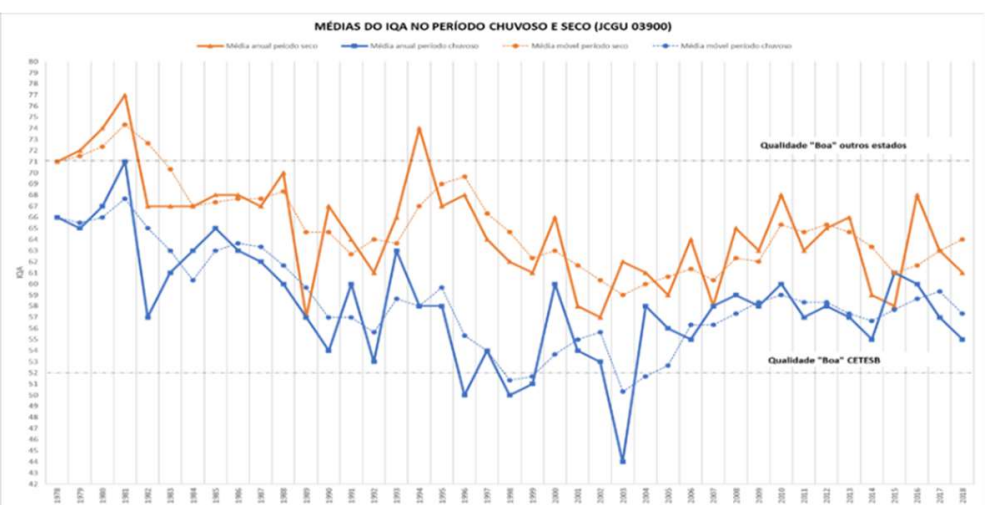

Figura 5: Médias anuais e médias móveis do IQA nos períodos chuvoso e seco, ponto JCGU 03900 - 1978 a 2018.

Fonte: CETESB (2019a).

De um modo geral, o IQA mais baixo no período chuvoso significa maior influência das cargas poluidoras difusas em relação às cargas pontuais, devido à lixiviação de uma maior quantidade poluentes pelo escoamento superficial. O lançamento de cargas pontuais ocorre nos dois períodos do ano, sendo que estas sofrem menos variação ao longo do tempo, mas mesmo com menores vazões e menor diluição dos poluentes na estiagem, os impactos sobre o corpo d'água, no caso, se mostraram ainda inferiores aos das cargas difusas.

Pode-se notar, ainda com base na Figura 5, que no período seco as médias móveis variaram de 74 em 1981 a 59 em 2003, o que é considerado, segundo os critérios da CETESB, uma classificação 'boa'. As médias anuais, por sua vez, variaram de 77 em 1981 a 57 em 1989 e 2002, classificação também 'boa'. No período chuvoso, as médias móveis tiveram uma variação de 68 ('boa') em 1981 a 50 ('razoável') em 2003 e as médias anuais, de 71 ('boa') em 1981 a 44 ('razoável') em 2003. Entretanto, segundo os critérios de outros estados, no período seco as médias móveis e anuais se enquadram respectivamente como 'boa' (1981) e 'razoável' (2003) e no período chuvoso, as médias móveis se enquadram como 'razoável' (1981) e 'ruim' (2003) e as médias anuais, como 'boa' (1981) e 'ruim' (2003).

\section{Índice de Qualidade das Águas para Proteção da Vida Aquática - IVA}

A Figura 6 apresenta a variação do IVA de 2003 a 2013, que apresenta uma tendência geral de melhora no período; entretanto, a partir de 2014 o índice teve uma mudança em sua qualidade, apresentando de maneira progressiva uma piora, até o ano de 2018. No ano de 2011 não houve determinação do IVA e a sua média móvel foi calculada por interpolação (média aritmética das médias anuais de 2010 e 2012).

Pode ser notado pelas Figuras 4 e 6 que, de um modo geral, no período de 2003 a 2012 a tendência de variação da média móvel do IVA é coerente com a do IQA, no sentido da melhoria da qualidade das águas e que de 2013 a 2018 também acompanha o IQA, mas com tendência de piora da qualidade. No entanto, observa-se que as oscilações (picos) das médias anuais do IVA são menos atenuadas ou menores que as do IQA. 


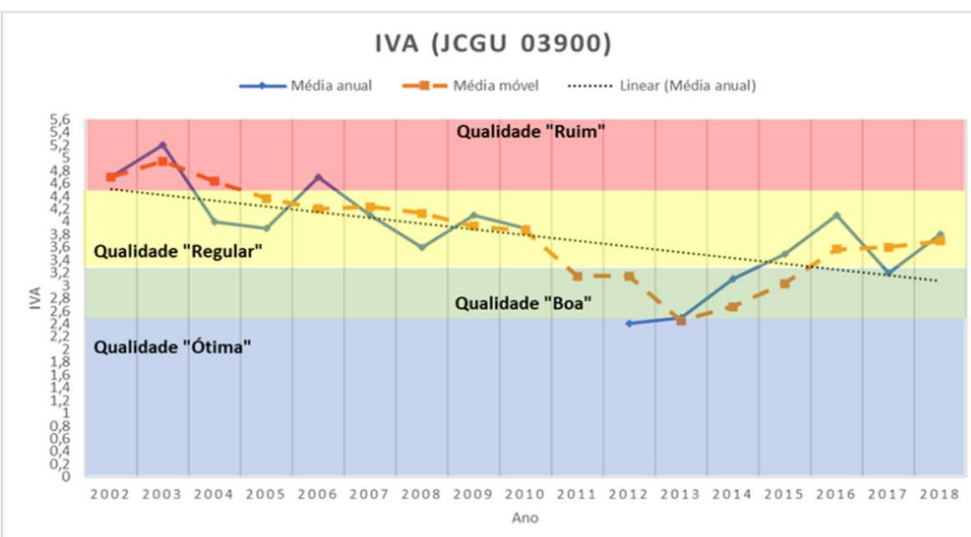

Figura 6: Médias anuais e médias móveis do IVA no ponto JCGU 03900 - 2002 a 2018. Fonte: CETESB (2019b).

Os melhores valores foram nos anos de 2012 e 2013, com um IVA de 2,4 e 2,5 respectivamente. $O$ pior valor foi em 2003 (5,2), mesmo ano do pior IQA obtido para o ponto em estudo. Esses dois índices apresentaram um comportamento muito semelhante ao longo do tempo, embora em 2016 tenha havido um comportamento contrário, com uma alta do IQA e piora do IVA (vide Figuras 4 e 6), o que pode ser explicado pelo lançamento de cargas tóxicas naquele ano, influenciando negativamente o IVA e não o IQA. Os resultados do IVA segundo a CETESB (2019b) podem sofrer influências negativas pelo grau de trofia, substâncias tóxicas e alteração de parâmetros essenciais à vida aquática (pH, Oxigênio Dissolvido e Toxicidade), reforçando a importância de se observar este índice parâmetro por parâmetro. As faixas de classificação do IVA utilizadas no Brasil, inclusive pela CETESB (CETESB, 2019b), são apresentadas no Quadro 2.

Quadro 2: Classificação do IVA adotada no Brasil.

\begin{tabular}{ll}
\hline Valor do IVA & Classificação do corpo d'água \\
\hline$\leq 2,5$ & Ótima \\
\hline $2,6 \leq$ IVA $\leq 3,3$ & Boa \\
\hline $3,4 \leq$ IVA $\leq 4,5$ & Regular \\
\hline $4,6 \leq$ IVA $\leq 6,7$ & Ruim \\
\hline IVA $>6,8$ & Péssima \\
\hline
\end{tabular}

Fonte: Adaptado de ANA (2009).

Observa-se pela Figura 6 e Quadro 2 que o IVA no período analisado possui classificação com tendências bastante diversificadas - 'ruim' (2002-2004), 'regular' (2005-2010 e 2016-2018), 'boa' (2011-2012 e 2014-2015) e 'ótima' (2013), o que mostra uma maior sensibilidade deste índice em relação ao IQA.

\section{IVA nos períodos chuvoso e seco}

Para o IVA, é possível observar na Figura 7 os resultados para os períodos de maior e menor precipitação. Da mesma forma que no gráfico da Figura 6, as médias móveis para o ano de 2011 foram determinadas por interpolação.

Observando os gráficos da Figura 7, nota-se que a qualidade das águas (IVA) no período seco é marcadamente superior à do período chuvoso, com exceção apenas de 2015, em que a média anual do período seco foi maior (ou pior) que a do chuvoso, permanecendo, entretanto, a média móvel de estiagem melhor que a do período chuvoso, o tempo todo. No geral, a tendência das médias móveis e anuais é de melhora de 2002 a 2013, mas com maiores oscilações para as anuais, principalmente no período chuvoso. 
De 2014 em diante as médias móveis tendem a piorar, até o final do período estudado. O mesmo ocorre em relação às médias anuais, mas sua a piora se dá antes, a partir de 2013. De qualquer forma, as tendências das médias móveis do IVA nos dois períodos são coerentes com as médias do IQA (vide Figuras 6 e 7).

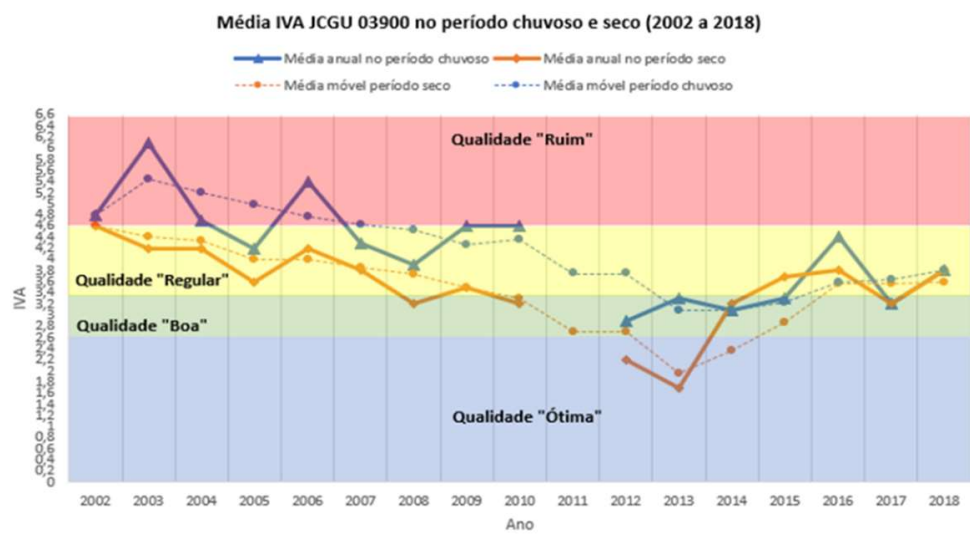

Figura 7: Médias anuais e médias moveis do IVA nos períodos chuvoso e seco, ponto JCGU 03900 - 2002 a 2018. Fonte: CETESB (2019b).

As médias móveis apresentaram para o período seco uma classificação 'regular' de 2002-2009 e 2016-2018; 'boa' de 2010-2012 e 2015; e 'ótima' de 2013-2014. As médias anuais variaram entre 4,6 ('ruim') em 2002 e 1,7 ('ótima') em 2012. No período chuvoso as médias móveis foram 'ruim' de 2002-2007; 'regular' 2008-2012 e 2016-2018; e 'boa' 2013-2015. As médias anuais variaram de 6,1 ('ruim') em 2002 a 2,9 ('boa') em 2013.

\section{CONCLUSÕES}

Os índices IQA e IVA se mostraram adequados para se verificar a tendência da variação da qualidade das águas do Rio Jacaré-Guaçu no ponto estudado e a longo prazo, sendo que de uma forma geral, os resultados obtidos relativos a esses índices foram coerentes entre si.

O IQA apresentou uma tendência geral de queda de qualidade nos 40 anos analisados (1978-2018), mas entre 2003 e 2018 houve uma relativa melhora, sem que a qualidade voltasse aos níveis observados ao final da década de 1970 e início da de 1980 (1978-1981). Pelos resultados, a classificação da qualidade das águas no período é considerada predominantemente 'boa', segundo os critérios adotados pela CETESB/SP, mas por critérios mais recentes, de outros estados brasileiros, a classificação seria predominantemente 'razoável', indicando a necessidade da CETESB rever/atualizar os seus critérios relativos ao IQA.

O IVA teve uma tendência de melhora desde o início de sua determinação, em 2002, mas que apresentou uma piora a partir de 2014, até o final do estudo. Os critérios de classificação do IVA são uniformes no Brasil e por eles, os resultados obtidos para o índice indicaram tendência de qualidade das águas que variou de no período de 'ruim' a 'ótima', com predomínio no tempo da classificação 'regular', o que indica a necessidade de esforços da CETESB e dos demais atores envolvidos no uso e gestão das águas na Sub-Bacia Hidrográfica do Rio Jacaré-Guaçu, no sentido de melhorar as condições e os parâmetros/indicadores relacionados à toxicidade e à trofia no Rio Jacaré-Guaçu.

Quando se analisa a influência dos períodos chuvoso e seco sobre a tendência de variação de ambos 
os índices, verifica-se que eles apresentam comportamento similar, com a qualidade tendendo claramente a ser melhor no período chuvoso. Este fato mostra um predomínio da poluição difusa, pelo escoamento superficial das águas pluviais, em relação à poluição pontual, pelo lançamento de efluentes, e indica a necessidade de priorizar o controle das fontes poluidoras difusas, de incrementar e conservar a cobertura de vegetação nativa (florestal) na Sub-Bacia Jacaré-Guaçu, bem como a vegetação ripária (matas ciliares) nas margens e nas áreas de preservação permanente ao longo do rio.

\section{REFERÊNCIAS}

ALVARES, C. A.; STAPE, J. L.; SENTELHAS, P. C.; GONCALVES, J. L. M.; SPAROVEK, G.. Köppen's climate classification map for Brazil. Meteorologische Zeitschrift, v.22, n.6, p.711-728, 2013. DOI: $\underline{\text { http://doi.org/10.1127/0941-2948/2013/0507 }}$

ANA. Agência Nacional de Águas. Indicadores de qualidade: Índice de qualidade das águas (IQA). Brasília: ANA, 2009.

ARARAQUARA. Comitê da Bacia Hidrográfica Tietê-Jacaré. Relatório de situação dos recursos hídricos 2018: Ano Base 2017. Araraquara, CBH-TJ, 2018.

BOSO, A. C. M. R.; GABRIEL, C. P. C.; GABRIEL FILHO, L. R. A.. Análise do desenvolvimento dos principais indicadores da qualidade da água. Periódico Eletrônico Fórum Ambiental da Alta Paulista, v.11, n.6, 2015. DOI: http://dx.doi.org/10.17271/1980082711620151265

BRANCO, S. M.; ROCHA, A. A.. Poluição, proteção e usos múltiplos de represas. São Paulo: Edgard Blucher, 1977.

BRASIL. Constituição da República Federativa do Brasil de 1988. Brasília: DOU, 1988.

CARVALHO, A. R.; SCHLITTLER, F. H. M.; TORNISIELO, V. L.. Relações da atividade agropecuária com parâmetros físicos químicos da água. Química Nova, v.23, n.5, p.618-622, 2000. DOI: http://dx.doi.org/10.1590/S0100-40422000000500009

CETESB. Companhia Ambiental do Estado de São Paulo. Qualidade das águas interiores no Estado de São Paulo: Relatórios 1978 a 2018. São Paulo, CETESB, 2019a.

CETESB. Companhia Ambiental do Estado de São Paulo. Qualidade das águas interiores no Estado de São Paulo: Relatórios 2003 a 2018. São Paulo, CETESB, 2019b.

CORREIO, L. N. C.; COCCONELLO, S. T.; MORAES, P. B.; GUEDES, H. A. S.; CENTENO, A. N.; CECCONELLO, S.

T.. Análise temporal da qualidade da água de um arroio no sul do Rio Grande do Sul. Revista Thema, Pelotas, v.14, p.109-119, 2016. Dol: https://doi.org/10.15536/thema.13.2016.109-119.363

CPTI. Cooperativa de Serviços, Pesquisas Tecnológicas e Industriais. Revisão do plano de bacia da Unidade de
Gerenciamento de Recursos Hídricos do Tietê/Jacaré: relatório técnico №. 402/08. São Paulo: CPTI, 2008.

DONADIO, N. M. M.; GALBIATTI, J. A.; PAULA, R. C.. Qualidade da água de nascentes com diferentes usos do solo na bacia hidrográfica do Córrego Rico. Engenharia Agrícola, v.25, n.1, p.115-125, 2005. DOI: http://dx.doi.org/10.1590/S0100-69162005000100013

EHLERS, R. S.. Análise de Séries Temporais. Departamento de Estatística, UFPR, 2005.

GALLO, Z.. Ethos, a grande morada humana: economia, ecologia e ética. Itu: Ottoni, 2007.

INSTITUTO PRÓ-TERRA. Plano diretor de restauração florestal da Unidade de Gerenciamento de Recursos Hídricos Tietê-Jacaré (UGRHI 13) visando a conservação dos recursos hídricos e a preservação da biodiversidade. Relatório Técnico Executivo. Jahu: Instituto Pró-Terra, 2013.

LOPES, F. B.; TEIXEIRA, A. S.; ANDRADE, E. M.; AQUINO, D. N.; ARAÚJO, L. F. P.. Mapa da qualidade das águas do rio Acaraú, pelo emprego do IQA e Geoprocessamento. Revista Ciência Agronômica, v.39, n.3, p.392-402, 2008.

PERROTA, M. M.; SALVADOR, E. D.; LOPES, R. C; D'AGOSTINO, L. Z.; PERUFFO, N.; GOEMS, S. D.; SACHS, L. L. B.; MEIRA, V. T.; GARCIA, M. G. M.; LACERDA FILHO, G. V.. Mapa Geológico do estado de São Paulo, escala 1:750000. Programa Geologia do Brasil - PGB. São Paulo: CPRM, 2005.

REBOUÇAS, A. C.; BRAGA, B.; TUNDISI, J. G.. Águas doces no Brasil: capital ecológico, uso e conservação. 3 ed. São Paulo: Escrituras, 2006. p.01-34.

SOUZA, V.; GALVANI, E.. Distribuição Espaço Temporal Da Precipitação Pluvial E Sua Interação Com O Relevo Na Bacia Do Rio Jacaré Guaçu (SP). Ciência e Natura, Santa Maria, v.39, p.110-124, 2017. DOI: http://doi.org/10.5902/2179460X27334

VETIVER. Vetiver Projetos Ambientais Ltda. Plano da Bacia Hidrográfica Tietê-Jacaré: Relatório I. Araraquara: $\mathrm{CBH}-\mathrm{TJ}$, 2016.

A CBPC - Companhia Brasileira de Produção Científica (CNPJ: 11.221.422/0001-03) detém os direitos materiais desta publicação. Os direitos referem-se à publicação do trabalho em qualquer parte do mundo, incluindo os direitos às renovações, expansões e disseminações da contribuição, bem como outros direitos subsidiários. Todos os trabalhos publicados eletronicamente poderão posteriormente ser publicados em coletâneas impressas sob coordenação da Sustenere Publishing, da Companhia Brasileira de Produção Científica e seus parceiros autorizados. Os (as) autores (as) posteriormente ser publicados em coletâneas impressas sob coordenação da Sustenere Publishing, da Companhia Brasileira de Produção Científica e seus parce
preservam os direitos autorais, mas não têm permissão para a publicação da contribuição em outro meio, impresso ou digital, em português ou em tradução. 